\title{
Spastic Quadreparesis - An Unusual Presentation of Sub-acute Combined Degenaration of Spinal Cord
}

\author{
MOHAMMAD SYEDUL ISLAM, ${ }^{1}$ AFROJA ALAM, ${ }^{2}$ MD ADNAN HASAN MASUD, ${ }^{3}$ MD ABUL KALAM AZAD, ${ }^{4}$ MD ABDUR RAHIM,
}

\begin{abstract}
We report a case of a 45-year-old gentleman presenting with numbness of both legs and hands. He has anemia, spastic quadriplegia with exageraterd tendon jerks with lose of vibration and position sense. Investigations revealed combined deficiency anemia with low serum vitamin $B_{12}$. His MRI of cervicel spine was normal. Endoscopically he had atrophic gastritis. Ultimately he was dignosed as a case of sub-acute combined degeneration of spinal cord due to pernicious anemia. Patient was treated with injection vitamin $B_{12}$ and well responded. On his followup, he had significant clinical improvement. This is a reversible condition if early diagnosis can be made and vitamin $B_{12}$ therapy promptly given. Delayed treatment can result in irreversible neurological impairment.
\end{abstract}

Keywords: Spastic quadriplegia, Subacute combined degeneration, Vitamin $B_{12}$ deficiency

\section{Introduction:}

Subacute combined degeneration is the classical metabolic disorder of spinal cord- it is due to vitamin B12 deficiency. It can also be caused by folate deficiency. Vitamin B12 (cyanocobalamin) is found essentially in all meat and dairy products. It is an essential vitamin for DNA and fatty acid synthesis, including myelin synthesis ${ }^{1}$. Vitamin B12 deficiency can be caused by gastrointestinal malabsorption, defective intrinsic factor deficiency in gastric parietal cells (pernicious anemia),gastrectomy, pancreatic insuffiency, disease of terminal ilium, fish tapeworm infestation, poor nourishment of food, vegetarians, genetic deficiency of methylmalonyl-CoA mutase. Patients may present with haematological (megaloblastic anaemia), gastrointestinal and neuro psychiatric manifestations. Vitamin B12 deficiency state results in decreased activity of cobalamin-dependent methylcobalamin esterase enzyme with the resultant elevated levels of methylmalonic acid, which is toxic to myelin.Both myelin sheaths and axons, are destroyed mainly in the white matter of the spinal cord. ${ }^{1,2}$

\section{Case summary}

A 45 years married male was presented with progressive weakness, numbness of limbs and difficulty in walking for 3

1. Research Assistant, Department of Medicine, Bangabandhu Sheikh Mujib Medical University (BSMMU), Shahbag, Dhaka, Bangladesh.

2. Assistant Professor (RP), Department of Medicine, BSMMU.

3. Consultant, Department of Medicine, BSMMU

4. Associate Professor, Department of Medicine, BSMMU.

5. Professor, Department of Medicine, BSMMU.

Correspondence : Dr. Mohammad Syedul Islam, Research Assistant, Department of Medicine, Bangabandhu Sheikh Mujib Medical University (BSMMU), Shahbag, Dhaka, Bangladesh. months. He had also anorexia, weight loss \& sore mouth for 1 year. He had normal bladder-bowel function, no history of trauma to neck or neckache. He was on average Bangladeshi diet. He was mildly anaemic, had smooth raw tongue and angular cheilosis. Neurological examination revealed slowness of mentation, but MMSE score was 28, muscle power of distal group were $3 / 5$ and proximal group were 4/5. All deep tendon reflexes were exaggerated with presence of ankle and patellar clonus with extensor plantar response. Gait was ataxic and spastic. There was impaired joint position $\&$ vibration sense in lower limbs up to medial malleolus that made our probable diagnosis of cervical myelopathy with differential diagnosis of Subacute combined degeneration of spinal cord. Other systemic examination revealed normal findings.

Investigation revealed, Complete blood picture showed $\mathrm{Hb}: 9$ gm/dl,ESR:40 mm/1 ${ }^{\text {st }}$ hour, WBC:4,000, Platelet:178,000,

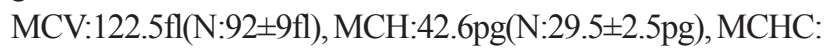
$34.8 \mathrm{gm} / \mathrm{dl}(\mathrm{N}: 33 \pm 1.5 \mathrm{gm} / \mathrm{dl})$. PBF showed macrocyte, schistocytes, nRBCS with normal WBC and Platelet. Serum $\mathrm{B}_{12}$ level was $<60 \mathrm{pg} / \mathrm{ml}$ (normal range 208-963 pg/ml) and Serum folate was $14.47 \mathrm{ng} / \mathrm{ml}(\mathrm{N}: 2.7-16.1 \mathrm{ng} / \mathrm{ml})$. Bone marrow aspiration showed hypercellular marrow, reduced M/E Ratio. Erythropoiesis is markedly hyperactive with megaloblastic changes. Granulopoiesis: Active and maturing into segmented forms with a few giant metamyelocytes. Megakeryocytes: Normal. Comments: Megaloblastic anaemia. Upper GI endoscopy reaveled relatively smooth mucosa of the body which was consistent with atropic gastritis. Histopathology of stomach biopsy revealed moderate to dense infiltration of lymphocytes and plasma cells in the lamina propiraa and atophy of the glandular epithelium, Giemsa stained sections show no Helicobactor pylori, finding consistent with atrophic gastritis without 
presence of any H.Pylory. (Fig: 1\&2). But Schilling test, antiparietal cell \& anti-intrinsic factor antibodies was not available to confirm pernicious anaemia. MRI of cervical spine was nomal (Fig: 3).

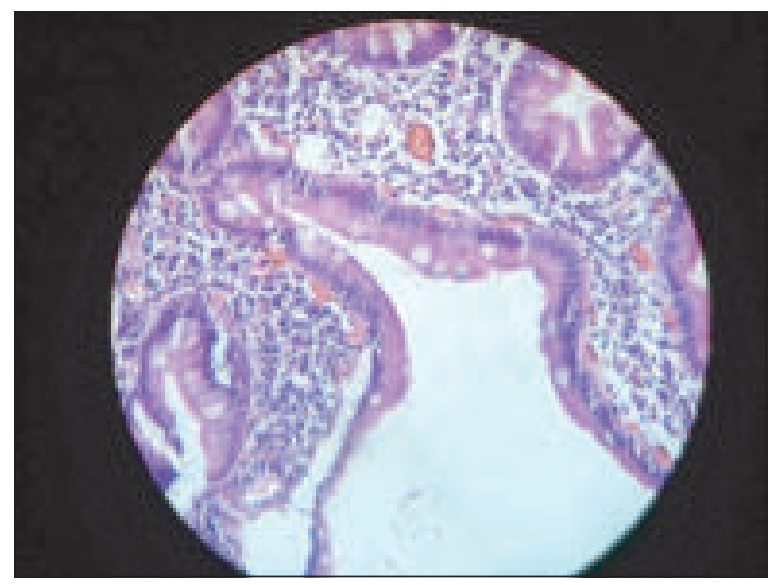

Fig.-1: Chronic Atrophic Gastritis.

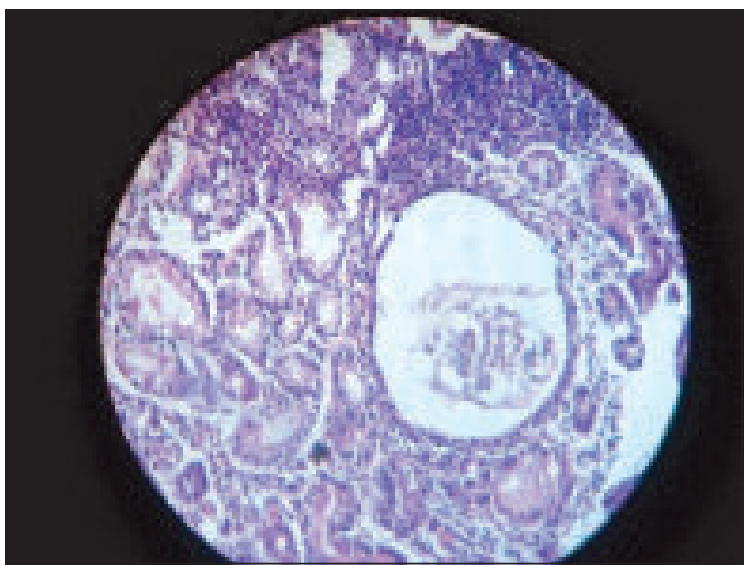

Fig.-2: Chronic Atrophic Gastritis.

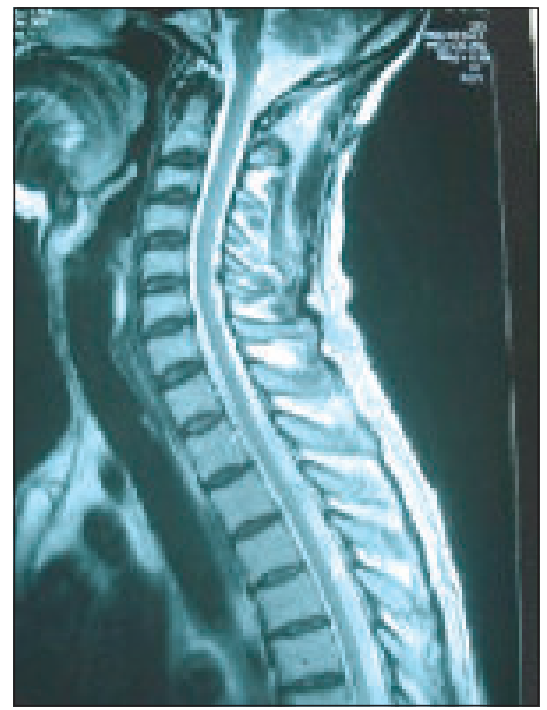

Fig.-3: MRI of cervical spine showed normal finding.
We concluded that this was a case of sub-acute combined degeneration of spinal cord due to Pernicious Anemia. We started inj. vit. $B_{12} \mathrm{i} / \mathrm{m}$ every alternate day for 5 doses and advised to continue life long in 3 months interval. Anaemia, sore tongue improved dramatically, but there was some improvement of neurological defects. Patient was discharged with partial improvement and with instructions for follow up. On his follow up he had gradual neurological improvement.

\section{Discussion}

The neuro-psychiatric manifestations involve the brain, spinal cord, optic nerve and peripheral nervous system. In the early stage of the disease, the spinal cord appears to be affected first ${ }^{2}$. The posterior columns and corticospinal tracts are specifically damaged, but the clinical picture is complicated by the early development of coexistent peripheral nerve damage. ${ }^{3}$ The posterior column involvement results in impairment of position and vibration sense and dysaesthesia. The onset of symptoms was usually insidious, with paresthesias in the hands and feet present in the majority of patients. Sensory peripheral neuropathy can be the sole manifestation of $\mathrm{B}_{12}$ deficiency. Paresthesias in the feet and distal loss of all modalities of sensation with loss of ankle jerks were observed. ${ }^{4}$ But in our case ankle and knee jerks were exaggerated with presence of ankle and patellar clonus. There was no feature of peripheral neuropathy which is an unusual presentation. The next most common complaints include weakness and unsteadiness of gait. Cerebral symptoms may occur and can include confusion, delusions, hallucinations, mental slowing, and depression. Loss of position or vibration sense is the most common abnormality. Motor impairment may range from only mild clumsiness to a spastic paraplegia. ${ }^{5}$ But in our case there was spastic quadriperesis which was also unusual presentation .Visual impairment can be seen; ophthalmological exam may show bilateral visual loss, optic atrophy, and centrocecal scotomata. Brainstem or cerebellar signs or even reversible coma may occur. ${ }^{6}$ Hematological abnormalities, including hypersegmentation of polymorphonuclear cells and a macrocytic anemia, can be seen; however, they may be completely absent at the time of neurological presentation. ${ }^{7}$ Current state-of-the-art testing uses serum cobalamin levels as a screening test, and the Schilling test, serum or urine methylmalonic acid and homocysteine determinations as confirmatory tests. A Schilling test detecting impaired intestinal absorption of vitamin $\mathrm{B}_{12}$, should be performed if there is enough clinical suspicion for the disease, and may reveal low vitamin $B_{12}$ absorption even when the serum level is normal. ${ }^{8}$ The presence of circulating antibodies to parietal 
cells in many of these patients suggests an underlying autoimmune disorder. Treatment of $\mathrm{B}_{12}$ deficiency depends on the cause and often includes monthly $\mathrm{B}_{12}$ intramuscular injections for life. ${ }^{9,10}$

\section{Conclusion}

Early diagnosis of subacute combined degeneration of the spinal cord is important because the condition is curable with prompt replacement therapy. The degree of resolution of clinical symptoms is inversely proportional to the duration and severity of Vitamin $B_{12}$ deficiency. In the event of delayed treatment, irreversible disabling neurological impairment may occur. Although the MRI findings of subacute combined degeneration are not specific but the features will arouse clinical suspicion of this treatable condition.As early diagnosis and treatment is often followed by reversal of the neurological deficits, emergency physicians should be vigilant for this uncommon condition.

\section{Conflict of Interest : None}

\section{References}

1. Wadia RS, Bandishti S, Kharche M. B12 and folate deficiency: incidence and clinical features. Neurol India, 2000; 48(4); 302-4.

2. So YT, Simon RP. Deficiency diseases of the nervous system. Vitamin $B_{12}$ deficiency. In: Bradley WG, Daroff RB, Fenichel
GM, editors. Neurology in clinical practice, 4th ed. Philadelphia, PA: Butterworth- Heinemann. 2004; 1694-7.

3. Healton EB, Savage DG, Brust JC. Neurologic aspects of cobalamin deficiency. Medicine (Baltimore). Jul 1991; 70(4):229-45.

4. Grossman RI, Yousem DM. Nondegenerative diseasesof the spine. Subacute combined degeneration (SCD). Neuroradiology. Philadelphia, PA: Mosby; 2003.804-5.

5. Srikanth SG, Jayakumar PN, Vasudev MK, Taly AB, Chandrashekar HS. MRI in subacute combined degeneration of spinal cord: a case report and review of literature. Neurol India 2002; 50(3):310-2.

6. Pittock SJ, Payne TA, Harper CM. Reversible myelopathy in a 34-year-old man with Vitamin B12 deficiency. Mayo Clin Proc 2002; 77(3):291-4.

7. Hemmer B, Glocker FX, Schumacher M, Deuschl G, Lucking $\mathrm{CH}$. Subacute combined degeneration: clinical, electrophysiological, and magnetic resonance imaging findings. J Neurol Neurosurg Psychiatry 1998; 65(6): 822-7.

8. Tartaglino LM, Flanders AE, Rapoport RJ. Intramedullary causes of myelopathy. Semin Ultrasound CT MR 1994; 15(3):158-88.

9. Samuels MA, Feske S. Office practice of neurology. New York: Churchill Livingstone; 1996. 1009-13.

10. Fauci AS, Braunwald E. Harrison's principles of internal medicine, 14th Ed. New York: McGraw-Hill; 1998. 653-8. 